\title{
Ações Iniciais do Projeto de Extensão Garotas Tech dos Sertões de Crateús para Captação e Retenção de Meninas aos Cursos de TI da UFC-Crateús
}

\author{
Lisieux Marie Marinho dos S. Andrade, Simone de Oliveira Santos, \\ Maria Roberia Rodrigues Gomes, Agatha Bhenares Alves Martins Rodrigues, \\ Ariadna Maria Carreiro de Miranda, Lucas Lima Sousa Torres, Claudia Sousa Barbosa \\ ${ }^{1}$ Universidade Federal do Ceará - Campus Crateús. BR-226, Km 03, Crateús - CE - Brasil \\ lisieuxandrade@ufc.br, simonedcrateus.ufc.br, \{roberiarodrigues.ufc, \\ agathabmartinsr, ariadnamiranda022, lucaslimasousatorres, claudiasousa683\}@gmail.com
}

\begin{abstract}
The university extension program Garotas Tech dos Sertões de Crateús intends to encourage female undergraduate students from Federal University of Ceará (UFC) - Campus of Crateús, as well as female students from either public and private regular and vocational schools, and also from needy communities, to getting closer to the Information Technology field. In order to achieve so, during its first year of activity, the program has developed motivational and informative projects, with the purpose of improving the retention rate of those students on campus, and creating a sense of group. For the outside public, a preliminary study of high school students overview was performed using a diagnostic survey, to which 291 students replied. The collected results reveal the necessity of a better approach between the University and local schools, as well as a good integration among college students of UFC-Crateús.
\end{abstract}

Resumo. O Grupo de Extensão Garotas Tech dos Sertões de Crateús tem por objetivo incentivar estudantes universitárias da Universidade Federal do Ceará- Campus Crateús, de escolas públicas ou privadas, do ensino médio ou profissionalizante, e das comunidades carentes a se aproximarem da área de Tecnologia da Informação. Para isso, em seu primeiro ano de atuação, promoveu práticas de caráter motivacional e informativa, visando melhorar a retenção das alunas do Campus e a formação de uma unidade de grupo. Ao público externo um estudo preliminar do perfil dos estudantes do ensino médio foi realizado por meio de questionário diagnóstico, tendo a participação de 291 alunos. Os resultados coletados revelam a necessidade da aproximação da universidade às escolas da região, e uma boa integração das estudantes da instituição.

\section{Introdução}

Estudos recentes da International Data Corporation - IDC revelaram o crescimento de 4,9\% da área de Tecnologia da Informação e Comunicação (TIC) no Brasil em 2020 [IDC 2020], mesmo com a crise financeira existente no país. Isso é o reflexo de um campo de trabalho promissor, que requer a cada ano um número elevado de profissionais qualificados para ingresso neste mercado. Conforme Softex [Softex 2020], há uma estimativa de 408 mil profissionais de Tecnologia da Informação (TI) para 2022. 
Apesar do crescimento da área e das ofertas de oportunidades no mercado de TI, a participação feminina neste mercado é extremamente baixa. Até 2014, em média, apenas $31 \%$ dos profissionais da área de TI eram mulheres [Nunes 2016]. Verificando tais índices e observando os cursos de graduação no país, pesquisas revelam elevada taxa de abandono em cursos da área de TI, a exemplo de [da Silva Zanato et al. 2018], e o número referente à evasão das alunas é ainda mais significativo [SBC 2018].

Desta forma, visando incentivar a participação feminina dentro dos cursos superiores da área da TI, grupos estão sendo constituídos em comunidades acadêmicas para esclarecer, discutir e difundir o tema. Uma destas iniciativas é o Programa Meninas Digitais $^{1}$ da Sociedade Brasileira de Computação (SBC), criado em 2011 após discursões em evento satélite do Congresso da Sociedade Brasileira de Computação (CSBC).

Alinhando a esta perspectiva e verificando as potenciais ações que podem contribuir com os cursos de Ciência da Computação (CC) e Sistemas de Informação (SI) ofertados na Universidade Federal do Ceará (UFC) - Campus Crateús, o Projeto de Extensão Garotas Tech dos Sertões de Crateús objetiva difundir o conhecimento da área, diminuir a taxa de evasão nos cursos e, com o passar do tempo, elevar o número de matrículas da comunidade feminina da região. Em seu primeiro ano de atividade, o projeto realizou análise do cenário de ingresso e abandono das estudantes da UFC-Crateús nos cursos de TI, análise da perspectiva de futuro de alunos de duas escolas da rede pública do ensino médio do município, promoção de palestras e minicurso.

\section{Cenário e Contextualização}

A UFC no contexto de expansão e interiorização do acesso ao ensino superior teve o município de Crateús escolhido para receber um campus da instituição. Atualmente, a oferta dos cursos escolhidos de forma estratégica para o desenvolvimento da região são na área da Engenharia e Tecnologia da Informação.

Os alunos matriculados nos cursos da área da TI representam 37,3\% do total de alunos do campus, e a representação feminina nestes um total de 20,2\%. Contudo, esta representação poderia ser mais expressiva já que as mulheres representam 67,7\% de todos os alunos que já evadiram nos cursos de TI do campus.

Esses dados se correlacionam aos do INEP, que segundo [da Silva Figueiredo et al. 2016], indicam uma regressão do número de mulheres matriculadas em cursos de TI. Em 1991 as mulheres representavam 34,9\% dos alunos matriculados, em 2013 passaram a 15,5\% dos ingressantes, e destas, apenas 13,6\% concluiram o curso. Conforme [Schmidt et al. 2016], a atração para cursos de tecnologia é maior em estudantes homens, que desde crianças recebem mais estimulos para área.

O ingresso de mulheres nos últimos cinco anos nos cursos de TI da UFC-Crateús pode ser visto no gráfico da Figura 1. A média de ingressantes nesse período no curso de CC é de $15,1 \%$ e 24,6\% em SI. Dadas essas informações, observa-se a necessidade de intensificar a aproximação da UFC-Crateús a este grupo mesmo antes da sua entrada no ensino superior, a fim de aprimorar as estratégias de retenção e potencializar as ações de captação de novas alunas.

\footnotetext{
${ }^{1}$ Disponível em: http://meninas.sbc.org.br/
} 


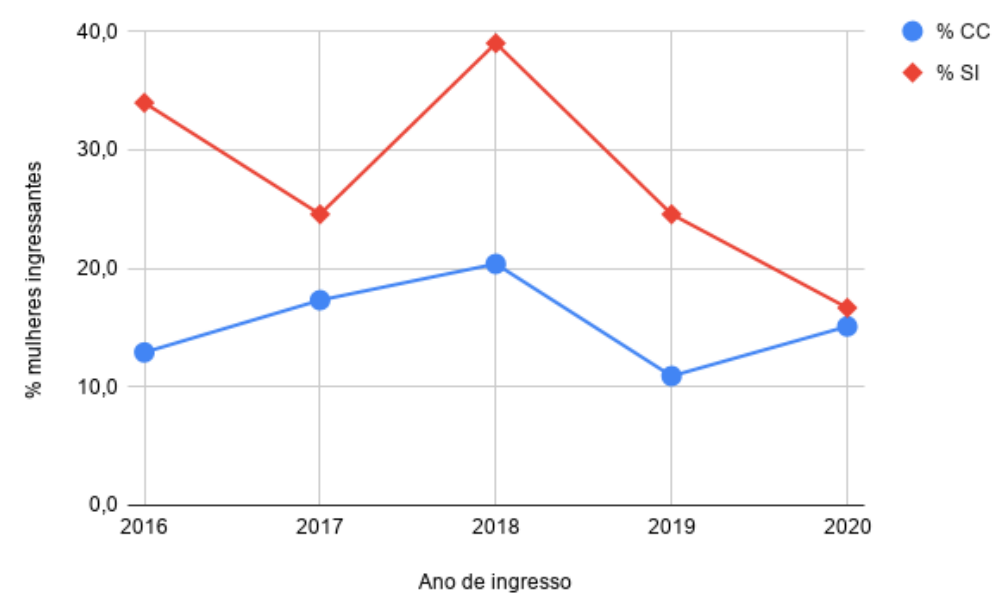

Figura 1. Porcentagem de ingressantes mulheres por curso

Dentro desse cenário, buscou-se conhecer mais os alunos do ensino médio da região, a fim de saber suas pretensões para o futuro.

\section{Atividades Externas - Análise}

Neste primeiro ano de projeto, foram visitadas duas escolas estaduais em 2019. Um questionário diagnóstico foi aplicado a 13 turmas de $2^{\circ}$ e $3^{\circ}$ anos, totalizando a participação de 291 alunos, dentre estes 148 do sexo feminino. O instrumento de coleta de dados foi estruturado em perguntas abertas sobre a escolaridade e ocupação dos pais, o desejo de ingressar no ensino superior, o conhecimento sobre quais cursos e universidades estão instalados na cidade, se possuem conhecimento sobre a atuação do profissional de TI, e se possuem conhecimento em informática básica.

Sobre as informações do núcleo familiar (mãe e pai), conforme Tabela 1, a escolaridade predominante entre os pais desses alunos é o ensino fundamental. Apenas 10 mães e 3 pais concluíram o ensino superior.

Tabela 1. Escolaridades - Mães e Pais

\begin{tabular}{|l|c|c|}
\hline \multicolumn{1}{|c|}{ Escolaridade } & Mãe & Pai \\
\hline Analfabeto & 11 & 26 \\
\hline Ensino Fundamental & 96 & 84 \\
\hline Ensino Médio completo & 54 & 32 \\
\hline Ensino Médio incompleto & 23 & 12 \\
\hline Ensino Superior completo & 10 & 3 \\
\hline Ensino Superior incompleto & 1 & 0 \\
\hline Pós-graduação & 1 & 1 \\
\hline Não sabe ou não respondeu & 95 & 133 \\
\hline
\end{tabular}

Quanto à ocupação profissional, 39 e 64 descrições distintas foram coletadas, respectivamente, para mães e pais, indicando a diversidade das atividades exercidas. Contudo, dentre as três atividades mais sinalizadas, conforme Tabela 2, a agricultura é predominante. 
Tabela 2. Ocupações Predominantes - Mães e Pais

\begin{tabular}{|c|l|c|}
\hline \multirow{4}{*}{ Mães } & Ocupação & Respostas recebidas \\
\cline { 2 - 3 } & Agricultora & 54 \\
\cline { 2 - 3 } & Dona de casa & 49 \\
\cline { 2 - 3 } Pais & Doméstica & 44 \\
\hline \hline \multirow{3}{*}{ Paicultor } & Agricul & 87 \\
\cline { 2 - 3 } & Pedreiro & 18 \\
\cline { 2 - 3 } & Comerciante & 10 \\
\hline
\end{tabular}

Do universo das estudantes, 98 possuem o desejo de ingressar na universidade, 13 não, e 38 não responderam ou não souberam opinar. Contudo, apenas 12 alunas indicaram ter conhecimento da existência dos cursos de TI na UFC-Crateús e 40 declararam ter conhecimento básico em informática. Porém, nenhum dos 291 alunos soube descrever a atuação de um profissional da TI.

Analisando as informações coletadas verifica-se a importância de esclarecer, discutir e difundir a área da TI, uma vez que das 148 alunas, 98 possuem desejo de ingressar no ensino superior, no entanto, poucas conhecem os cursos ofertados na UFC-Crateús.

\section{Atividades Internas - Construindo Laços}

Tendo a percepção da necessidade de fortalecer o núcleo interno das alunas e o senso de pertencimento ao curso, foram realizadas palestras com rodas de conversa, minicurso, e atividades que promovem o bem estar e a saúde mental.

As rodas de conversa foram direcionadas em duas temáticas: a carreira acadêmica e o mercado profissional de TI. A conversa que versou sobre carreira acadêmica foi mediada por uma docente que compartilhou sua trajetória desde a graduação até a sua atuação na universidade, mostrando os desafios, motivações e a atuação feminina na TI ao longo dos anos. A conversa na vertente do mercado de TI trouxe profissionais que já possuem experiência, e a conversa girou em torno da carreira profissional, ofertas de vagas, entrevistas de emprego e qualificação. Nestes encontros foi possível partilhar as dificuldades e superações encontradas na vivência acadêmica, o ingresso e as exigências do mercado, a importância da individualidade feminina e as remunerações médias atuais.

Um minicurso sobre Teste de Software foi elaborado e ministrado pelas alunas vinculadas ao Projeto de Extensão, contou com a presença de 31 alunos que relataram a satisfação da participação do encontro, e solicitaram a realização de mais atividades semelhantes. Neste momento, além da abordagem prática e teórica sobre o tema, foi também realizada uma iteração de quebra-gelo no início da atividade e uma dinâmica sobre projeto de vida no final do encontro.

Como atividades de bem estar e saúde mental, mensalmente foram desenvolvidas práticas de yoga e meditação, como meio de auxiliar o processo de concentração, respiração, postura e relaxamento em meio as atividades acadêmicas. Os encontros foram guiados por instrutora capacitada e contou com participação mista de alunos, não só dos cursos de TI, mas também dos demais cursos do campus.

Além destas atividades voltadas para público feminino, foi também realizado um momento exclusivo ao homens, uma conversa sobre masculinidades e violência de gênero. 


\section{Considerações e Trabalhos Futuros}

Retenção e captação de alunos é um processo difícil que envolve diversos fatores. Este projeto de extensão busca compreender e combater os fatores que favorecem a baixa entrada e permanência de alunas nos cursos de Ciência da Computação e Sistemas de Informação da UFC-Crateús.

Em seu primeiro ano de execução, o projeto obteve êxito nas atividades externas e internas à instituição. Com visita externa a duas escolas do ensino médio público um primeiro retrato do perfil dos alunos foi revelado quanto à escolaridade e ocupação exercida pelo núcleo familiar (pai e mãe), interesse de ingressar no ensino superior e conhecimento sobre a UFC-Crateús e os cursos ofertados na área de TI. As atividades internas revelaram o interesse e a necessidade do processo de integração para esclarecer, desmistificar, intensificar o papel feminino na área de TI e unir as alunas que compõem os cursos da instituição.

Como atividades futuras, pretende-se expandir a integração promovendo o processo de diagnóstico do perfil interno das alunas, realizar atividades de projeto de vida, intensificar as rodas de conversa, promoção de minicurso e palestras. E como atividades externas, dar continuidade em pesquisa mais profunda sobre as pretensões para o futuro dos estudantes das demais escolas da região, realizar o confronto dos perfis dos alunos do ensino público, privado e técnico profissionalizante, e promover a imersão das alunas do ensino médio em temáticas da TI por meio de oficinas e palestras.

\section{Referências}

da Silva Figueiredo, K., da Silva Neto, P. C., and Maciel, C. (2016). Meninas digitais regional mato grosso: Práticas motivacionais no ensino médio para a equidade de gêneros nas carreiras e cursos de computação e tecnologias. Anais do $X$ Women in Information Technology.

da Silva Zanato, K. Y., Ventura, T. M., and Ribeiro, J. M. (2018). Análise da evasão de alunos da área de tecnologia da informação por meio de um banco de dados orientado a grafos. Revista Eletrônica Argentina-Brasil de Tecnologias da Informação e da Comunicação, 1(8).

IDC (2020). Mercado de TIC deve crescer 4,9\% no brasil em 2020. https:// wWw. idc.com/getdoc.jsp?containerId=prLA 46093420 . Acessado em: 17/04/2020.

Nunes, J. H. (2016). Gênero e raça no trabalho em tecnologia da informação (ti). Ciências Sociais Unisinos, 52(3):383-395.

SBC (2018). Educação superior em computação, estatísticas 2017. Sociedade Brasileira de Computação-SBC.

Schmidt, A. E., de Britto, H. P., and Koehler, M. D. (2016). Levantamento e análise dos dados da presença feminina discente no curso de bacharelado em sistemas de informação do instituto federal catarinense, campus camboriú. Anais do X Women in Information Technology.

Softex (2020). Brasil Mais TI oferece vagas de trabalho. https://www. softex. br/brasil-mais-ti-oferece-vagas-de-trabalho/. Acessado em: 17/04/2020. 